\title{
Article \\ Synthesis and Characterization of Transparent Biodegradable Chitosan: Exopolysaccharide Composite Films Plasticized by Bio-Derived 1,3-Propanediol
}

\author{
Narisetty Vivek ${ }^{1,2,3} \oplus^{\infty}$, Nishant Gopalan ${ }^{2,3,4}$, Satyajit Das ${ }^{5}$, Keerthi Sasikumar ${ }^{2,3}$, Raveendran Sindhu ${ }^{2} \mathbb{D}_{\text {, }}$ \\ Kesavan Madhavan Nampoothiri ${ }^{2}$, Ashok Pandey ${ }^{6}$ (i) and Parameswaran Binod ${ }^{2, *}$ (i) \\ 1 Centre for Climate and Environmental Protection, School of Water, Energy and Environment, \\ Cranfield University, Cranfield MK43 0AL, UK; viveknarisetty@gmail.com \\ 2 Microbial Processes and Technology Division, CSIR-National Institute for Interdisciplinary Science and \\ Technology (CSIR-NIIST), Thiruvananthapuram 695019, Kerala, India; nishantg4429@gmail.com (N.G.); \\ keerthikee1991@gmail.com (K.S.); sindhurgcb@gmail.com (R.S.); madhavan85@hotmail.com (K.M.N.) \\ 3 Academy of Scientific and Innovative Research (AcSIR), Ghaziabad 201002, Uttar Pradesh, India \\ 4 Biotechnology Engineering Department, VVP Engineering College, Virda-Vajadi, Kalawad Road, \\ Rajkot 360005, Gujarat, India \\ 5 Photosciences and Photonics Section, Chemical Sciences and Technology Division, CSIR-National Institute for \\ Interdisciplinary Science and Technology (CSIR-NIIST), Thiruvananthapuram 695019, Kerala, India; \\ satyajitdas.0911@gmail.com \\ 6 Centre for Innovation and Translational Research, CSIR-Indian Institute of Toxicology Research (CSIR-IITR), \\ Lucknow 226001, Uttar Pradesh, India; ashokpandey1956@gmail.com \\ * Correspondence: binodkannur@niist.res.in; Tel.: +91-471-2515361; Fax: +91-471-2491712
}

check for updates

Citation: Vivek, N.; Gopalan, N.; Das, S.; Sasikumar, K.; Sindhu, R.; Nampoothiri, K.M.; Pandey, A.;

Binod, P. Synthesis and

Characterization of Transparent Biodegradable Chitosan:

Exopolysaccharide Composite Films Plasticized by Bio-Derived

1,3-Propanediol. Sustain. Chem. 2021,

2, 49-62. https://doi.org/

$10.3390 /$ suschem 2010004

Received: 27 November 2020

Accepted: 25 January 2021

Published: 2 February 2021

Publisher's Note: MDPI stays neutral with regard to jurisdictional claims in published maps and institutional affiliations.

Copyright: (c) 2021 by the authors. Licensee MDPI, Basel, Switzerland. This article is an open access article distributed under the terms and conditions of the Creative Commons Attribution (CC BY) license (https:// creativecommons.org/licenses/by/ $4.0 /)$.

\begin{abstract}
In this study, chitosan-based composite films blended with a dextran like exopolysaccharide derived from lactic acid bacteria were prepared using the solvent casting method. Later, these composite films were plasticized with 1,3-propanediol (1,3-PDO) produced biologically using biodiesel derived crude glycerol. Further, their physical properties, such as tensile strength, water vapor barrier, thermal behavior, and antioxidant properties, were tested. In comparison to the control chitosan-exopolysaccharide films, 1,3-PDO plasticized films increased tensile strengths (20.08 vs. $43.33 \mathrm{MPa}$ ) with an elongation percentage (\%E) of 20.73 , which was two times more than the control films. As a polymer composite, the Fourier transform infrared (FTIR) spectrum displayed the characteristic peaks at $1000 \mathrm{~cm}^{-1}, 1500 \mathrm{~cm}^{-1}$, and $3000-3500 \mathrm{~cm}^{-1}$ to describe the functional groups related to chitosan, exopolysaccharide, and 1,3-PDOThe thermogravimetric analysis displayed a significant three-step degradation at $100-105^{\circ} \mathrm{C}, 250-400{ }^{\circ} \mathrm{C}$, and $600{ }^{\circ} \mathrm{C}$, where $100 \%$ of the films were degraded. The plasticized films were observed to have enhanced water solubility (51\%) and rate of moisture absorption (193\%). The plasticized films displayed enhanced physico-chemical properties, anti-oxidant properties, and were $100 \%$ biodegradable.
\end{abstract}

Keywords: chitosan; exopolysaccharides; 1,3-propanediol; plasticizer; composites

\section{Introduction}

Plastics have been a part of day-to-day life since the 1950s. The packaging industry is the largest consumer of plastics. Globally, an estimate of 320 million tons of plastic are used for food packaging from which a significant amount are converted to waste. These synthetic polymers (plastics) are durable, non-degradable, and cannot be eliminated from usage. These plastic wastes from various sources were found to be accumulated, resulting in growing landfills. If burned, the gases emitted have greenhouse effects and are prone to air pollution. These non-degradable plastics also become an extreme threat to natural resources, mostly affecting the water bodies and living beings in them. However, there are many measures taken to recycle reusable plastics and incinerate non-reusable plastics. Still, the percentage of waste tackling through these measures is not enough compared to the 
rate of production and consumption. Hence, with increased population growth and market demand for plastics, along with the limitation of non-renewable (petroleum) substrates, there is prodigious attention and interest towards renewable sources for the production of biopolymers or bio-plastics. Various research groups worked on the microbial synthesis of polyhydroxyalkanoates (PHA) [1,2], and polylactic acid (PLA) [3] as a substituent for synthetic polymers. However, these polymers have limitations to be addressed in production yields, as well as ecological compatibility, before attaining commercial status.

Edible and biodegradable carbohydrate-based polymers composed of polysaccharides (starch, chitosan, kefiran, pullulan, and carboxymethyl cellulose), proteins (gelatin, casein, and soy protein) with different characteristic features (i.e., anti-microbial), and antioxidant activity were considered as suitable and sustainable renewable alternatives for petroleumderived plastics $[4,5]$. In these polysaccharides, starch was widely used for bio-plastics production but the starch polymer has various limitations, such as retrogradation during storage, i.e., reorganizing of the amylose and amylopectin structure resulting in new crystalline structures. Eventually, the characteristic properties of the starch polymer is changed [5]. However, the heteropolymer chitosan is also well known for the film-forming property. Chitin is the most abundant heteropolysaccharide after cellulose is found in this nature. Discovered in 1811 by French professor Henri Braconnot, chitin has more environmentally friendly characteristics, as it is biocompatible and biodegradable [6]. Chitosan is the deacetylated derivative of chitosan heteropolymer. Chitin and chitosan are random copolymers of $N$-acetyl-D-glucosamine (NAG) and D-glucosamine (NG), linked by $\beta-(1-4)$ glycosidic bonds. Chitin heteropolysaccharide have predominant NAG units and NG units for chitosan in the polymeric chains [6]. Chitin can be obtained from insects/crustacean shells and few fungal cell walls [6]. Either through enzymatic or chemical deacetylation, chitin can be converted to chitosan. When the deacetylation of chitosan reached $50 \%$ (based on polymer), the solubilized form in the aqueous acidic media becomes chitosan. The solubilization occurs due to protonation of the NH2 functional group, which can be observed on the 2nd carbon position on the NG repeat units. The polycationic behavior of chitosan $\left(\mathrm{R}_{-} \mathrm{NH}_{3}{ }^{+}\right)$after the deacetylation $\left(\mathrm{R}-\mathrm{NH}-\mathrm{Co}-\mathrm{CH}_{3}\right)$ provides a good film-forming property to the polymer and also increases water solubility [7]. To stabilize the polycationic chitosan, counter ions either in the form of lactic, acetic, or formic acid were required to stabilize the film. The film properties can be increased by the addition of plasticizers such as glycerol, isosorbide, and sorbitol, or antioxidants such as tocopherol and ferulic acid. The importance of chitosan being used as film-forming component is due to its biodegradable and biocompatible nature, along with its ease in solubility and non-toxicity. Chitosan has profound applications in biomedicine (i.e., burn and wound dressings), food, cosmetics (i.e., hair and skincare), pharmaceuticals (i.e., encapsulating agent), agriculture (i.e., biopesticide), and wastewater treatment (i.e., bio-flocculent) [8].

1,3-propanediol (1,3-PDO), a monomer derived from glycerol or corn glucose, has recently gained importance in the building of polymers, especially polyester, polytrimethylene terephthalate (PTT) formed by transesterification of 1,3-PDO, and terephthalic acid. Being structurally similar to glycerol despite the lack of one hydroxyl $(-\mathrm{OH})$ group at the 2nd carbon, this monomer has the properties to plasticize the composite films.

The chitosan films are rigid and require plasticizers to reduce the frictional forces between the adjacent polymer chains. Mostly chitosan films can be used in packaging. During the synthesis of biodegradable plastics for packaging, the main characteristics to be considered are mechanical strength, transparency, flexibility, gases, and water vapor permeability [5,9-13]. The ideal green plasticizers used for improving the physicochemical properties of the biopolymers should be non-toxic, miscible with the polymer, efficient in improving the strength, resistance to leaching, and low cost. Various bio-plasticizers reported were isosorbide, glycerol, sugar alcohols, citrate, castor oil, and fatty esters [14].

This research aimed to demonstrate and create awareness of the simple and efficient green synthesis of transparent and high-performance CEPS (chitosan exopolysaccharide) and CEPS-PDO (1,3-propanediol plasticized chitosan exopolysaccharide) plasticized 
biodegradable composite films that can be used in the packaging industry. Moreover, this research examined the influence of 1,3-propanediol as a green plasticizer compared to commercially available plasticizers. The characterization of these films revealed the unique properties and competitiveness with commercial synthetic plastics.

\section{Materials and Methods}

\subsection{Materials}

Chitosan has a molecular weight of 3800-20,000 Da (Daltons) and a $>75 \%$ degree of deacetylation. This was procured from Hi-media Labs, Mumbai, India. Dextrans, i.e., EPS (exopolysaccharides), with an average molecular weight of $2380 \mathrm{KDa}$ was used for composite blends and purified from food-grade lactic acid bacterium at the Microbial Processing and Technology Division, CSIR-National Institute for Interdisciplinary Science and Technology [15]. 1,3-propanediol was used as the plasticizer and was produced and purified via the methods described in our previous work [16-18].

\subsection{Film Formation}

The films were made using solvent evaporation or the solvent casting method $[19,20]$. At first, a 1\% v/v acetic acid solution was prepared using glacial acetic acid and distilled water. Later, a known amount $(2 \% w / v)$ of chitosan was added and mixed using a magnetic stirrer until the solution was clear. The solution was degassed using Elma ultrasonic sonicator. The viscous chitosan solution was poured into casting trays made of polyethylene terephthalate films. For the composite blend films, 1:1 w/w ratio of dextran, i.e., exopolysaccharide $(2 \% w / v)$ solution, was added to the chitosan solution before degassing. For the plasticized CEPS composite films, 0.5:1 w/w of the 1,3-propanediol to the whole polymer (chitosan + EPS) was added before degassing and, later, the degassed solutions were poured into different casting trays and incubated at $40{ }^{\circ} \mathrm{C}$ overnight (Supplementary Figure S1). The films thus obtained were used for further characterization.

\subsection{Characterization of the Films}

\subsubsection{Film Thickness and Tensile Strength}

The thickness of the film was measured using a screw gauge. The value for the thickness measurement used for tensile strength calculations was obtained by measuring the thickness of the film samples at three positions along the length of $20 \times 110 \mathrm{~mm}$ films. The values were used to calculate the film's tensile strength. The precision of the thickness measurements was $\pm 5 \%$. The tensile strength of the material was tested using the Universal Testing Instrument Model H5KS (Tinius Olsen, Horsham, Pennsylvania, PA, USA) fitted with a $100 \mathrm{~N}$ static load cell, with a crosshead speed of $50 \mathrm{~mm} / \mathrm{min}$, and extension of $100 \mathrm{~mm}$. The initial grip separation was $50 \mathrm{~mm}$, according to the standard testing method (ASTM 1995). The films were cut into strips $10 \mathrm{~mm}$ wide and $110 \mathrm{~mm}$ long; they were mounted between cardboard grips $(40 \mathrm{~mm} \times 30 \mathrm{~mm})$ using an adhesive to perform the experiment.

\subsubsection{Scanning Electron Microscopy (SEM)}

The study was employed using JSM-5600 LV scanning electron microscope of JEOL, Tokyo, Japan. To understand the surface morphology of the edges of the broken films obtained after tensile strength analysis. The dried samples were mounted on a metal stub and sputtered with gold to make the sample conductive. The images were taken at an accelerating voltage of $10 \mathrm{kV}$.

\subsubsection{Fourier Transform Infrared Spectroscopy (FTIR)}

The monomeric composition of these composite blended films was characterized using FTIR spectra recorded using a Shimadzu IR Tracer 100 Fourier transform infrared spectrophotometer (Shimadzu, Kyoto, Japan). 


\subsubsection{Thermogravimetric Analysis (TGA)}

The thermal behaviors of the films were studied via thermogravimetric analysis using a TG-DTA 6200 (SII Nano-technology Inc., Tokyo, Japan). The substance (9.0 mg) was subjected to a temperature range of $30-300{ }^{\circ} \mathrm{C}$ under a normal atmosphere at a rate of $15^{\circ} \mathrm{C} / \mathrm{min}$ and the corresponding weight loss was determined.

\subsubsection{UV-Vis Spectroscopy}

The composite blend films were cut into $20 \mathrm{~mm} \times 20 \mathrm{~mm}$ square pieces and were subjected to solid state UV-Visible spectroscopy using a Shimadzu 2100 UV-Visible spectrophotometer. The absorbance and transmittance of these composite films were recorded from $300 \mathrm{~nm}$ to $800 \mathrm{~nm}$. The transparency of the film played a crucial role in the acceptability of the film for food packaging uses, thus making this test important.

\subsubsection{Wide-Angle X-ray Diffraction (WAXD)}

To understand the X-ray diffraction pattern of these composite films, which elucidate the information regarding the structural properties and intermolecular bonding nature, WAXD measurements were carried out using a XEUSS SAXS/WAXS system using a Genix micro source from Xenocs. The methodology followed for the measurement and sample preparation was done according to the report by Nagendra et al. [21].

\subsubsection{Water Transfer Rate of Blend Films}

The water transfer rate of the chitosan dextran blend films (control and with the addition of ferulic acid) was tested according to the ASTM E96 method, specifically the wet cup method. The test involved the addition of $10 \mathrm{~mL}$ deionized water to a $150 \mathrm{~mL}$ screw cap bottle and which was sealed using a hollow cap and paraffin wax. The setup was then transferred to a desiccator's chamber with dry silica gel. The weights of each screw cap bottle were recorded every two hours and the loss in weight of the water from the vessels was ultimately used to calculate the water transfer rate for each film.

\subsubsection{Antioxidant Activity}

Biopolymers or composite films with antioxidant or hydrogen peroxide radical scavenging activity would be an added benefit for food and packaging applications. The antioxidant activity of chitosan exopolysaccharide blend composite films (CEPS) and plasticized composite films (CEPSPDO) was carried out using hydrogen peroxide radical scavenging assay [22] with slight modifications. The methanol extract of composite films was carried out by adding $500 \mathrm{mg}$ film pieces in $15 \mathrm{~mL}$ methanol and sonicating the mixture for $2 \mathrm{~h}$. Then, the mixture was centrifuged to collect the supernatant. To perform the assay, the solution of $40 \mathrm{mM}$ of $30 \%$ hydrogen peroxide was prepared using a $50 \mathrm{mM}$ phosphate buffer ( $\mathrm{pH}$ 7.4). After the incubation of methanolic extract, $500 \mu \mathrm{L}$ of the supernatant was added to $3 \mathrm{~mL}$ of assay mixture and incubated at $37^{\circ} \mathrm{C}$ for $10 \mathrm{~min}$. Later, absorbance was noted at $230 \mathrm{~nm}$ using a Shimadzu UV spectrophotometer. Moreover, $50 \mathrm{mM}$ phosphate buffer without any added hydrogen peroxide was used as a blank. The antioxidant activity was measured using Equation (1).

$$
\mathrm{H}_{2} \mathrm{O}_{2} \text { radical antioxidant activity }(\%)=\left[1-\left(\mathrm{A}_{\text {Sample }} / \mathrm{A}_{\text {Control }}\right)\right] \times 100
$$

A Sample: $_{\text {Absorbance of sample. }}$

$\mathrm{A}_{\text {Control }}$ : Absorbance of control.

\subsubsection{Moisture Content}

As the known characteristic of a biopolymer, the composite films may absorb moisture from the surrounding environment. The amount of moisture absorbed by the film from the surrounding environment occurred until equilibrium was attained for the moisture content of the films. In this study, CEPS and CEPSPDO composite film moisture content 
was measured by drying the $20 \mathrm{~mm} \times 20 \mathrm{~mm}$ square pieces of films in an oven at $105^{\circ} \mathrm{C}$ until constant weight was attained. The initial weight of the film was denoted as $A_{i}$ and the final dry weight as $A_{f}$. The moisture content was calculated using Equation (2).

$$
\text { Moisture content } \%=\frac{A_{i}-A_{f}}{A_{i}} \times 100
$$

\subsubsection{Water Absorption}

The water absorption capacity of the composite films was determined by immersing the dried films with weight $A_{f}$ obtained from the above experiment, in $50 \mathrm{~mL}$ distilled water. An increase in weight was monitored over a while until a constant weight was observed. After attaining the level of saturation, the final weight of the sample was recorded and denoted as $A_{w}$. The water absorption capacity of the composite film was measured using Equation (3).

$$
\text { Water absorption } \%=\frac{A_{w}-A_{f}}{A_{f}} \times 100
$$

\subsubsection{Film Solubility}

The monomers used in the preparation of these blend films were of biological origin and thus could be easily miscible in water. Therefore, the percentage of weight loss of films was measured by observing the solubility. To determine the water solubility of the films, the films were cut into $20 \mathrm{~mm} \times 20 \mathrm{~mm}$ square pieces and kept in a vacuum desiccator to remove the moisture content and then the initial weight of the sample was noted as $F_{i}$. Later, the film pieces were immersed in $50 \mathrm{~mL}$ distilled water and kept overnight at room temperature. The samples were dried at $105{ }^{\circ} \mathrm{C}$ until a constant weight was attained and the final weight was recorded as $F_{f}$. The percentage solubility of composite films was measured using Equation (4).

$$
\text { Film solubility }(\%)=\frac{F_{i}-F_{f}}{F_{i}} \times 100
$$

\subsubsection{Biodegradability of Composite Films}

Though the composite films synthesized in this study used the polymers and monomers derived from a biological origin - such as chitosan from shrimp shell waste, EPS from a food-grade lactic acid bacterium, and 1,3-propanediol produced from a Lactobacillus brevis N1E9.3.3 strain using biodiesel derived crude glycerol-it would be appropriate to prove that these bio-composite films could be degraded in a natural environment without causing any damage to the natural ecosystem. Here, we made a compost soil using vermicompost and biogas reactor digestate. Later, CS films and CEPSPDO films of $1.0 \mathrm{~g}$ weight were placed inside the soil and incubated at room temperature to observe the decrease in weight for the films.

\section{Results and Discussion}

\subsection{Film Casting, as Well as Physical and Mechanical Characteristics}

Intact and transparent chitosan (CS), chitosan exopolysaccharide (CEPS), and plasticized chitosan exopolysaccharide (CEPSPDO) films were obtained via the solvent casting method (Figure 1). CS and CEPS films were fragile compared to CEPSPDO films, as the plasticizer 1,3-propanediol imparted flexible characteristics to the film.

The functionality of a plasticizer can be explained as a molecule with lesser molecular weight and weakened intermolecular interactions between the polymeric chains, thus resulting in a less dense structure with an increased elongation percentage. The physical properties of the above mentioned films are summarized in Table 1. It was observed that the addition of exopolysaccharides to the chitosan solution decreased the tensile strength, the force of elongation, and elongation percentage. However, by adding the 
plasticizer to the exopolysaccharide blended chitosan films, all properties were found to increase by $39.19 \%$ for tensile strength, decrease by $67.38 \%$ for the max elongation force, and increase by $94 \%$ for the elongation percentage. This was observed as a result of plasticizing chitosan exopolysaccharide blends in comparison to chitosan films. Even the phenomenon was attributed to physical imaging of broken corners in films obtained after mechanical testing (Figure 2). CS films (Figure 2A) have a homogenous appearance and CEPS films (Figure 2B) look a little fragile and less compact. The plasticization with $50 \%$ 1,3-propanediol (Figure 2C) in the cross-section of the films looks compact, elastic, and flexible. Even in the literature, hydrophilic plasticizers such as glycerol, ethylene glycol, and polyethylene glycol resulted in brittle films. However, 1,3-PDO plasticized composite films were observed to be intact [23]. Because the CSEPS films were fragile without plasticizers, further physiochemical characterization experiments were carried out using CS and CEPSPDO films.

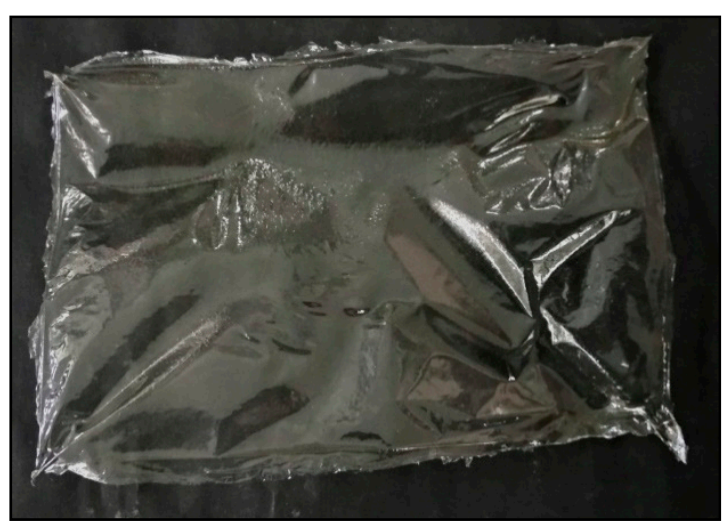

(A)

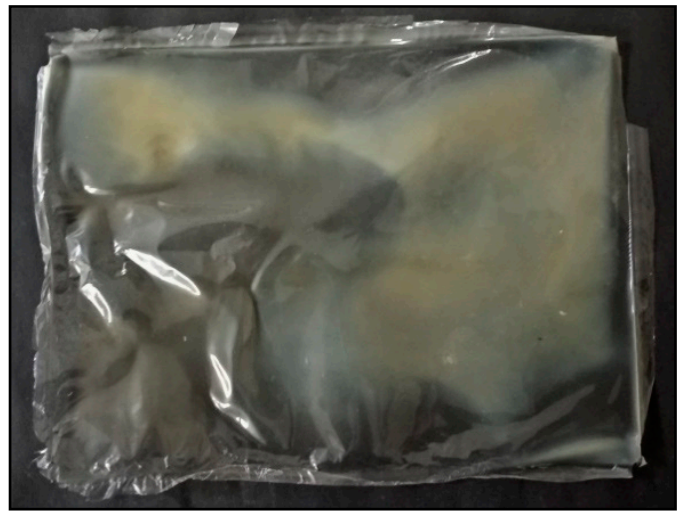

(B)

Figure 1. (A) Chitosan (CS) film; (B) plasticized chitosan exopolysaccharide (CEPSPDO) film.

Table 1. Mechanical characteristics of the composite films obtained using the universal testing instrument model H5KS (Tinius Olsen, Horsham, PA, USA) (ASTM 1995).

\begin{tabular}{cccccc}
\hline \multirow{2}{*}{ Film } & $\begin{array}{c}\text { Tensile } \\
\mathbf{M P a}\end{array}$ & $\begin{array}{c}\text { Max Force } \\
\mathbf{N}\end{array}$ & $\begin{array}{c}\text { Elongation } \\
\mathbf{\%}\end{array}$ & $\begin{array}{c}\text { Thickness } \\
\mathbf{m m}\end{array}$ & $\begin{array}{c}\text { Width } \\
\mathbf{m m}\end{array}$ \\
\hline CS & 31.13 & 39.85 & 10.64 & 0.05 & 20 \\
CEPS & 20.08 & 12.85 & 10.00 & 0.05 & 20 \\
CEPSPDO & 43.33 & 13.00 & 20.73 & 0.05 & 20 \\
\hline
\end{tabular}

CEPS film plasticization was done using 1,3-PDO, which increased the tensile stress from 20.08 to 43.33 $\mathrm{MPa}$ (Figure 3). On the contrary, pure chitosan films were observed to have TS 31.13 MPa, which was similar to earlier studies by Zeynep Kalaycıŏglu et al. [24]. The chitosan and blend films showed a linear stress-strain curve as reported in earlier studies [25]. Initially, the CEPS films were brittle, but plasticization improved the interaction between the two polymers chitosan and EPS. Even the interactions between free $\mathrm{OH}$ groups in $\mathrm{PDO}$ and $\mathrm{NH}_{2}$ groups of chitosan contributed to improvements in tensile stress and elongation percentage (Table 1). Although glycerol was used as a plasticizer in the previous studies, we observed that glycerol plasticized chitosan films, decreased tensile strength, and, in comparison to 1,3-PDO, improved the film forming properties of chitosan and exopolysaccharide. 


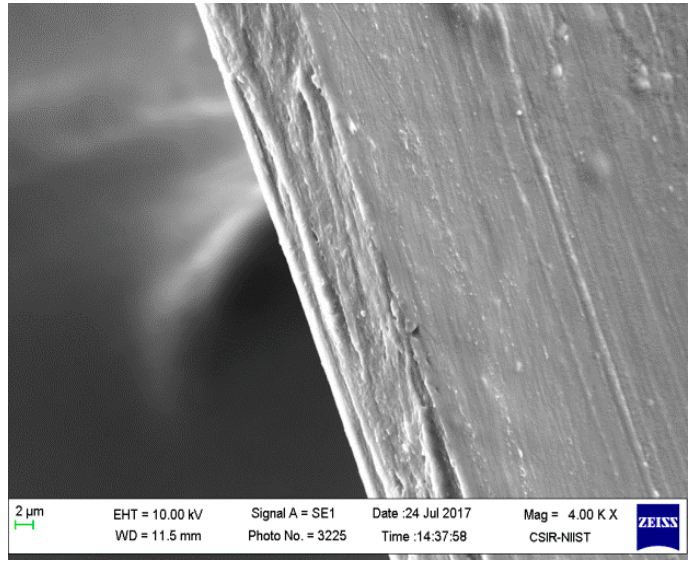

(A)

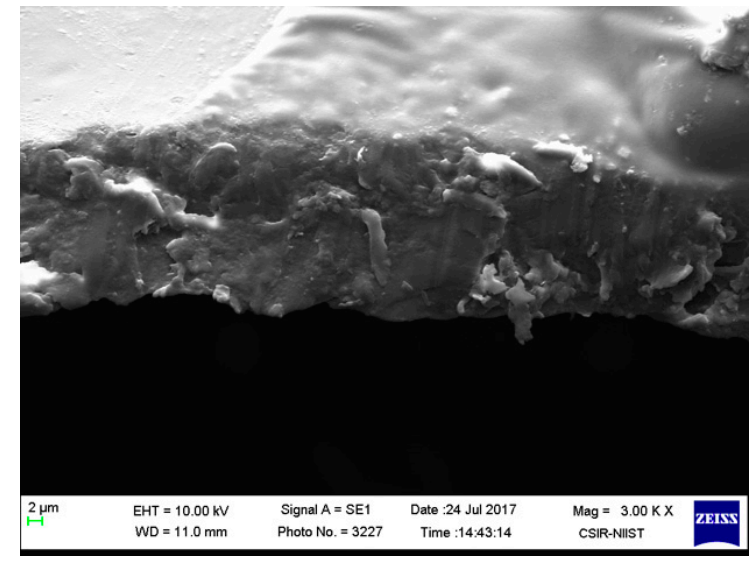

(B)

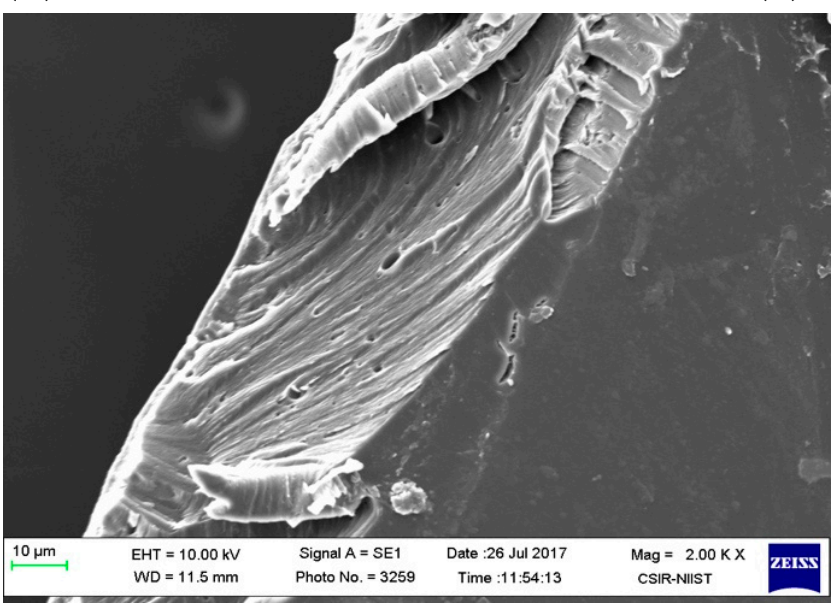

(C)

Figure 2. SEM images of composite blend films (A) chitosan (CS), (B) chitosan exopolysaccharide (CEPS), and (C) chitosan EPS/1,3-PDO (CEPSPDO).

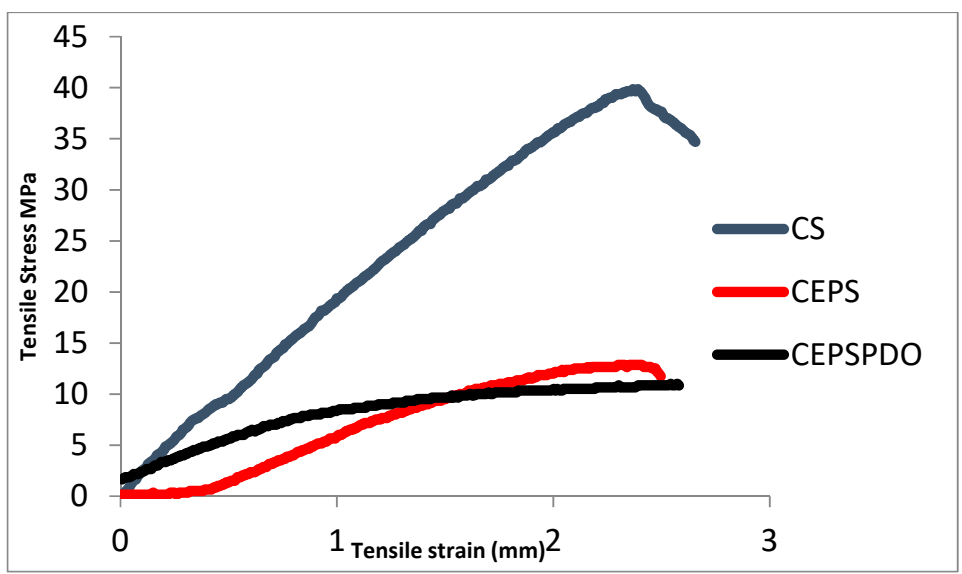

Figure 3. Stress-strain curves of composite blend films chitosan (CS), chitosan exopolysaccharide (CEPS), and chitosan EPS and 1,3-PDO (CEPSPDO).

\subsection{Fourier Transform Infrared Spectroscopy (FTIR)}

The FTIR spectrum analyzed the free functional groups present in the molecule to understand the change in the structure after synthesizing the composite films. In Figure 4, we observed the IR spectrum of CS, CEPS, and CEPSPDO films. A strong band in the region $3000-3500 \mathrm{~cm}^{-1}$ corresponded to $\mathrm{N}-\mathrm{H}$ and $\mathrm{O}-\mathrm{H}$ bonds, as well as intramolecular 
hydrogen bonding. The characteristic bands close to $3000 \mathrm{~cm}^{-1}$ indicated that C-H were symmetrical and asymmetrical. These peaks were characteristic of a typical polysaccharide. A distinguishing peak of $1500 \mathrm{~cm}^{-1}$ corresponded to residual $\mathrm{N}$-acetyl groups $\left(1645 \mathrm{~cm}^{-1}\right.$ ( $\mathrm{C}=\mathrm{O}$ stretching of amide $\mathrm{I}$ and $1325 \mathrm{~cm}^{-1} \mathrm{C}-\mathrm{N}$ stretching of amide III)), which were observed in CS, CEPS, and CEPSPDO films. In the control chitosan film, a characteristic band at $1589 \mathrm{~cm}^{-1}$ corresponded to $\mathrm{N}-\mathrm{H}$ bending of primary amine. However, in test films, the peak was not prominent and there was a possibility of overlap with other bands. The two adjacent bands after $1325 \mathrm{~cm}^{-1}, 1423 \mathrm{~cm}^{-1}$, and $1375 \mathrm{~cm}^{-1}$ represented $\mathrm{CH}_{2}$ bending and $\mathrm{CH}_{3}$ symmetry. The band close to $1000 \mathrm{~cm}^{-1}$ corresponded to $\mathrm{C}-\mathrm{O}$ stretching. The dextran like exopolysaccharide had repeating units of glucose, which had major $-\mathrm{OH}$ groups correspond to a band in the region at $3000-3500 \mathrm{~cm}^{-1}$. $\mathrm{CH}$-groups had a symmetry and asymmetry close to $3000 \mathrm{~cm}^{-1}$. Similarly, the plasticizer 1,3-propanediol structurally consisted of $-\mathrm{OH}$ groups and $-\mathrm{CH}$ symmetric regions [26,27].

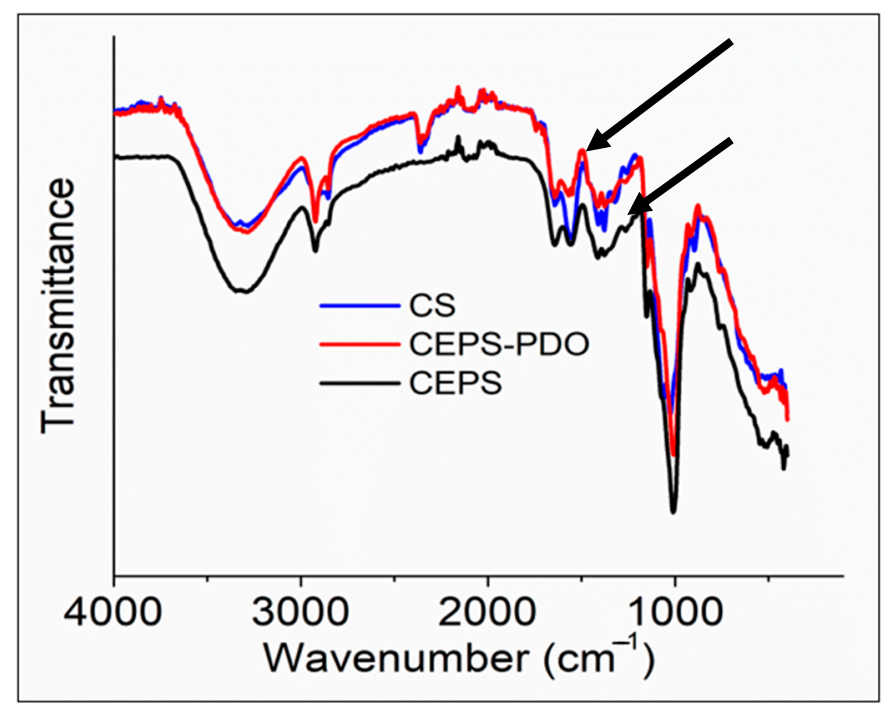

Figure 4. FTIR Spectra of chitosan (CS), chitosan exopolysaccharide (CEPS), and plasticized chitosan exopolysaccharide (CEPSPDO) films. The upper arrow corresponds to a peak at $1645 \mathrm{~cm}^{-1}$ and the down arrow corresponds to a peak at $1325 \mathrm{~cm}^{-1}$.

\subsection{UV-Vis Spectroscopy}

In FTIR, we understood the presence of various chemical functionalities for CS and other blend composite films. In UV-Vis spectrum, we determined the presence of interand intra-covalent and non-covalent interactions in the monomers of composite films. The covalent interactions were detected in the presence of organic molecules that absorbed light at a particular wavelength (Figure 5). Those chemical entities in all the films lacked extended chemical bonds, and it appeared to be transparent from $400 \mathrm{~nm}$ to $800 \mathrm{~nm}$. Chitosan is composed of randomly distributed D-glucosamine and $N$-acetyl-D-glucosamine, which contains only covalent bonds. Therefore, organic molecules capable of absorbing light at a particular wavelength match well with previous reports. In Figure 5, we observed no significant optical bands in the spectra from $350-800 \mathrm{~nm}$. By chemical modification with exopolysaccharide and 1,3-PDO, the optical density was enhanced in the range of 300-350 nm, which was also well supported by the literature. As a result, the CEPSPDO film appeared to be opaque in nature [28,29]. 


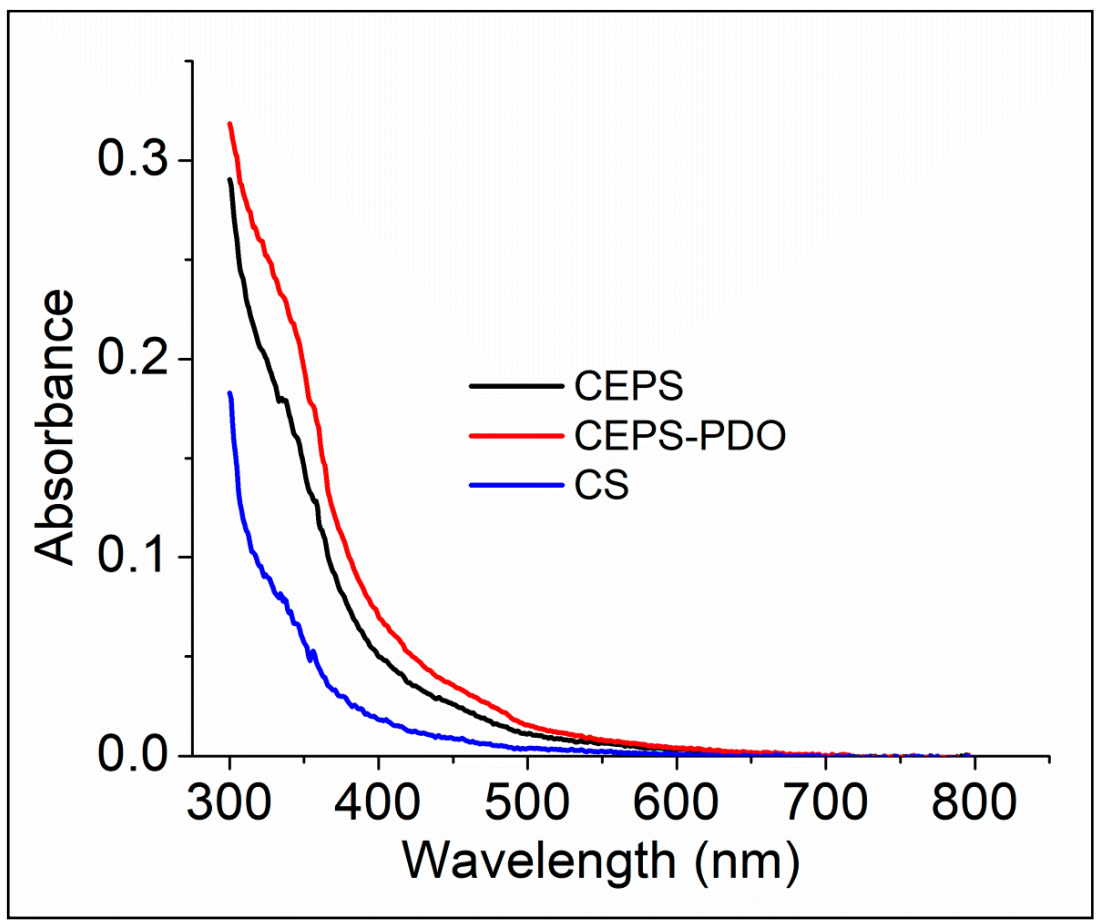

Figure 5. UV-absorbance spectra of chitosan (CS), chitosan exopolysaccharide (CEPS), and plasticized chitosan exopolysaccharide (CEPSPDO) films.

\subsection{Thermogravimetric Analysis (TGA)}

The TGA analysis of CS, CEPS, and CEPSPDO films were carried out to understand the thermal stability and degradation pattern in response to a temperature increase from 30-800 ${ }^{\circ} \mathrm{C}$ at a rate of $10^{\circ} \mathrm{C} / \mathrm{min}$. The TGA pattern of films CS (A), CEPS (B), and CEPSPDO (C), are represented in Figure 6. The pattern of thermal degradation in all the films were similar because of the bonding in chitosan and exopolysaccharides, and even the presence of $\mathrm{CH}_{2} \mathrm{OH}$ groups in chitosan, exopolysaccharide, and 1,3-propanediol. With regard to the three patterns in the degradation pattern, the initial loss rose to $100-105^{\circ} \mathrm{C}$, which represents the removal of water molecules and other volatiles. Until the second mass loss from $250-400{ }^{\circ} \mathrm{C}$, the films were observed to be stable. The second degradation step corresponded to the amine group's degradation for the chitosan polymer. The film was unstable and there was a gradual decrease in the film's mass when the temperature reached $600{ }^{\circ} \mathrm{C}$, wherein $100 \%$ degradation of the film was observed (Figure 5). The observed results were compared with previous studies using glycerol as the plasticizer. The addition of glycerol as the plasticizer did not have a significant influence on thermal stability. However, 1,3-PDO improved the thermal stability over $50{ }^{\circ} \mathrm{C}$ [30].

\subsection{Wide- and Small-Angle X-ray Scattering (WAXS/SAXS)}

$\mathrm{X}$-ray diffraction analyses are widely used to characterize packing order and crystallinity of materials in all forms. The characteristic X-ray scattering peaks for chitosan films (CS) align with those in the literature [28], where a broad diffraction in the range of $20-21^{\circ}$ has been shown due to its intermolecular hydrogen bonding and other van der Waals interactions for polymer chains. A noticeable diffraction peak at $2 \theta$ of $9-10^{\circ}$ (Figure 7) was believed to occur for a better-ordered arrangement in CS compared to other composite films. Overall, the pattern of the spectrum proved that there was an absence of crystalline structures in the composite films. Three CS, CEPS, and CEPSPDO films were amorphous in structure, and the large area between $2 \theta$ of $10-30^{\circ}$ represented the films moisture content. Although chitosan is semi-crystalline, the composite films prepared are amorphous, which may be due to the solvent casting method's reorganization. Our results were in agreement with several chitosan and other synthesized composite films [31-35]. 


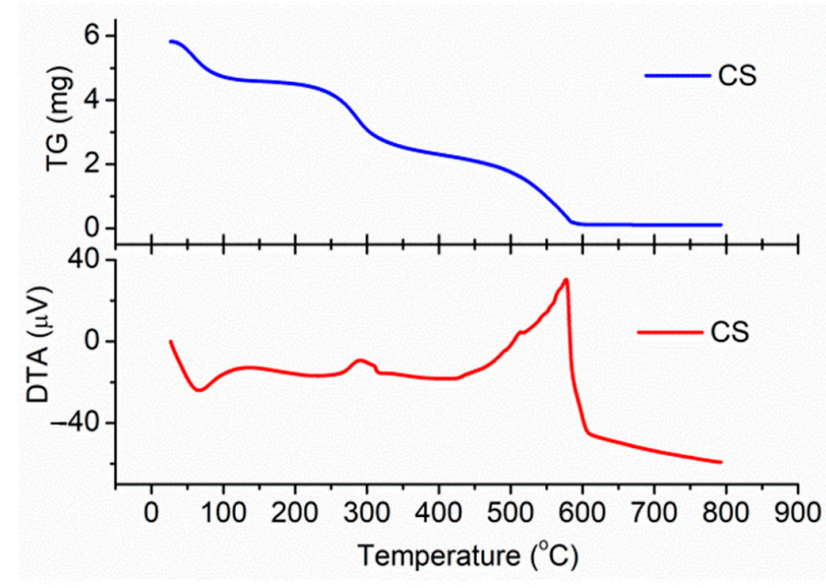

(A)

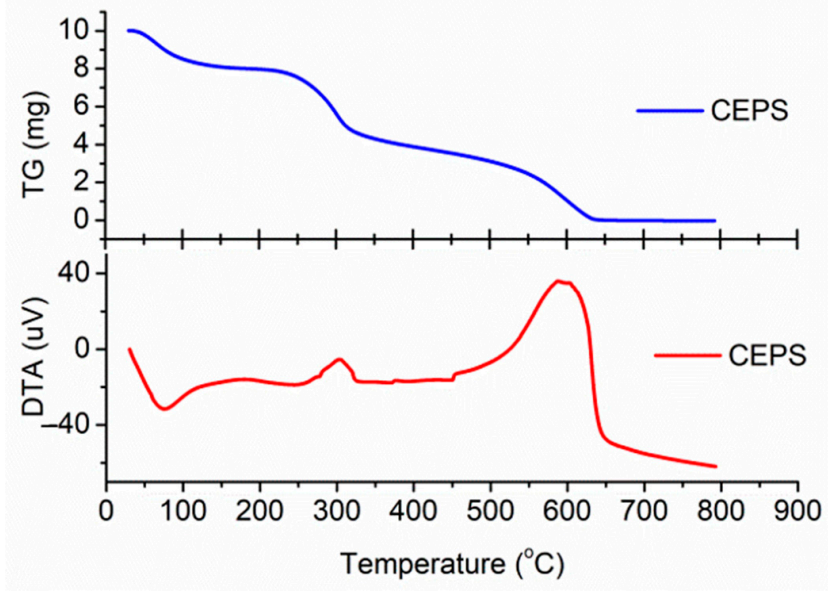

(B)
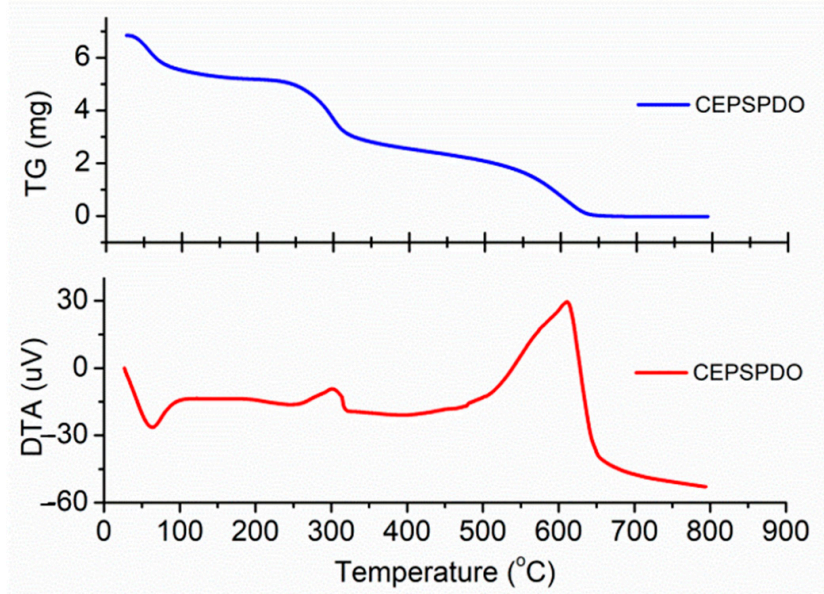

(C)

Figure 6. Thermogravimetric Analysis (TGA) and Derivative thermogravimetric DTG spectrum of (A) chitosan (CS), (B) chitosan exopolysaccharide (CEPS), and (C) plasticized chitosan exopolysaccharide (CEPSPDO) films.

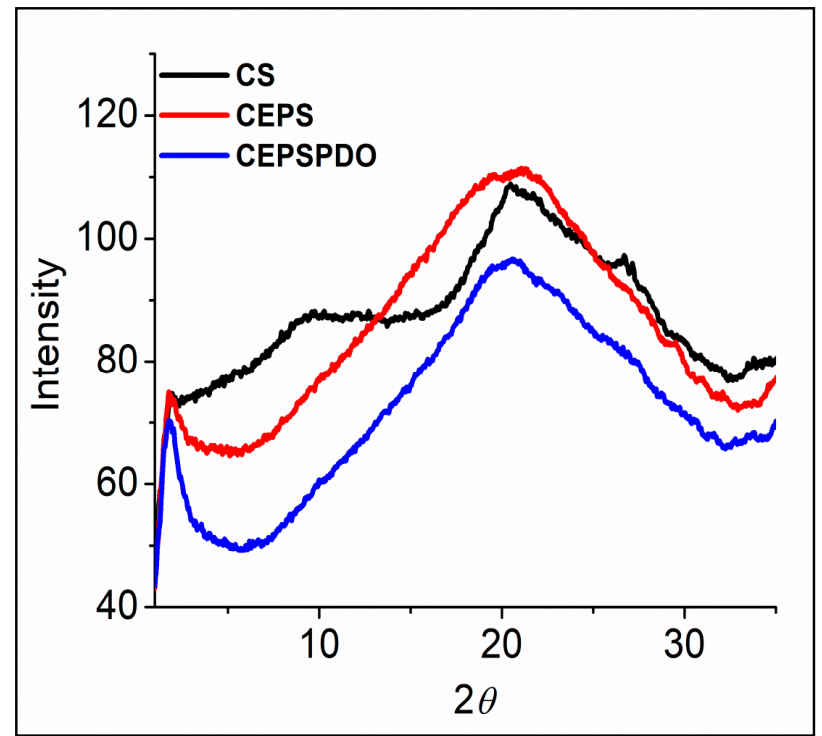

Figure 7. X-ray diffraction patterns of chitosan (CS), chitosan exopolysaccharide (CEPS), and plasticized chitosan exopolysaccharide (CEPSPDO) composite films. 


\subsection{Water Vapor Transfer Rate}

In food (dry and fresh) packaging, the packing materials act as a barrier between the surrounding environment and the packed food. The phenomenon plays a major role with regard to moisture content, i.e., if the barrier is easily accessible for the moisture then the dry food may lose the moisture into the environment, thus causing deterioration of material and quality. However, in our studies (Table 2), the water vapor transfer rate between the chitosan and plasticized chitosan exopolysaccharide films was shown to have fewer values compared to the results presented by Priyadarshi et al. [31]. Priyadarshi et al. found promising results for plasticized and cross-linked the chitosan films using glycerol and citric acid. Moreover, Reddy et al. found that 1,3-PDO was a better plasticizer than glycerol.

Table 2. Physiochemical, water vapor transfer rate, and antioxidant activity of chitosan, plasticized chitosan, and exopolysaccharide composite blend films.

\begin{tabular}{|c|c|c|c|c|c|}
\hline \multirow[t]{2}{*}{ Film Type } & \multicolumn{3}{|c|}{ Physiochemical Properties } & \multirow[b]{2}{*}{$\begin{array}{l}\text { Antioxidant } \\
\text { Activity (\%) }\end{array}$} & \multirow[b]{2}{*}{$\begin{array}{c}\text { Water Vapor } \\
\text { Transfer Rate } \\
\left.\text { (g/m } / \mathrm{m}^{2} / \mathrm{d}\right)\end{array}$} \\
\hline & $\begin{array}{c}\text { Moisture Content } \\
(\%)\end{array}$ & $\begin{array}{c}\text { Moisture } \\
\text { Absorption } \\
(\%)\end{array}$ & $\begin{array}{l}\text { Film } \\
\text { Solubility } \\
(\%)\end{array}$ & & \\
\hline CS & 8.42 & 137.17 & 19.15 & 40.1 & 429.6 \\
\hline CEPSPDO & 10.30 & 193.91 & 51.48 & 28.6 & 424.8 \\
\hline
\end{tabular}

\subsection{Anti-Oxidant Activity}

The Fenton reaction - in which hydrogen peroxide can be oxidized to release hydroxyl group radicals-occurs when hydrogen peroxide enters biological cells by crossing the barrier membrane and causing cell cytotoxicity. Antioxidants are a group of synthetic or bioderived chemical components that prevent the oxidizing property of hydrogen peroxide. In the food packaging industry, packaging materials with antioxidant properties have an advantage because they prevent food oxidation. From the observed results between the chitosan films, plasticized chitosan, and exopolysaccharide films, $28.6 \%$ (Table 2) reduced oxidative activity. The reason for reduced activity was due to lower concentrations of chitosan in CEPSPDO films. However, there are earlier works that found that antioxidant activity for plasticized films can be improved by incorporating cross-linkers such as citric acid [31], ferulic acid, and palmitic acid. Similarly, the addition of Eucalyptus globulus essential oils in chitosan films resulted in $60 \%$ antioxidant activity [22], yet the cost of film production is uneconomical to use these essential oils. Therefore, utilization of bio-derived monomers and polymers such as 1,3-PDO, exopolysaccharide, and chitosan are a preferred alternative to petrochemical-derived plastics [33].

\subsection{Moisture Content, Moisture Absorption, and Film Solubility}

The polymers used in CS and CEPSPDO films, chitosan, and exopolysaccharides can interact with water molecules due to the presence of hydroxyl groups and amine groups. Because there is no chemical reaction between these polymers, the free hydroxyl groups and amine groups are available for hydrogen bonding between the polymer and water molecules, which was confirmed by an increase in $22.32 \%$ moisture content and $41.36 \%$ moisture absorption rate. Even the explanation was in acceptance with film solubility, i.e., $51.48 \%$ of CEPSPDO films were soluble in water, compared to $19.15 \%$ of chitosan films (Table 2). This is a huge advantage for composite blend films. When the composite films were immersed in water, the polymer components absorbed the water molecules, resulting in the loosening of a compact polymer matrix. Other components, such as EPS and 1,3-PDO, are easily miscible in water. Thus, these components were released from the composite film, resulting in higher solubility. These days, the threat of petrochemical-derived plastics in the aquatic ecosystem is often discussed, especially as to whether or not these plastics can be replaced with bio-composite blend materials. If they can be, then a massive environmental disaster will be avoided [30,33-36]. 


\subsection{Biodegradability of Composite Films}

Knowing the environmental impact of petroleum-derived plastics on the natural ecosystem, chitosan, chitosan exopolysaccharide, and plasticized chitosan exopolysaccharide composite films show biodegradation pattern in the natural environment, where soil compost was prepared using vermicompost soil and dried biogas digestate. Soil compost was then transferred into disposable water cups and $1.0 \mathrm{~g}$ weighed films were kept in the soil and incubated for a week at room temperature. Because biogas digestate is a rich source of aerobic and anaerobic microorganisms, and vermicompost serves as a rich nitrogen source, all films degraded $100 \%$, and there was no sign of any composite blend film particles after incubation.

\section{Conclusions}

Biodegradable 1,3-PDO plasticized chitosan exopolysaccharide composite films were prepared using a simple solvent casting method. The physical and structural characterization revealed that the incorporation of 1,3-propanediol as a plasticizer increased the flexibility of CEPS films. The stability of the films were studied using a TGA analysis and observed a complete degradation at $600{ }^{\circ} \mathrm{C}$. The physico-chemical properties of CEPSPDO films were observed to be superior to the neat chitosan films. The CEPSPDO film has a lesser water transfer rate $\left(424.8 \mathrm{~g} / \mathrm{m}^{2} / \mathrm{d}\right)$ and higher water solubility $(51 \%)$ than CS films and glycerol, which is a well-known plasticizer for biodegradable films. In this study, we observed a novel plasticizer: 1,3-PDO. With the observed thermal, mechanical, physical, and biodegradable properties, the 1,3-PDO plasticized composite blend films showed recognizable eco-friendly characteristics unlike commercial petrochemical packaging material used in food industries.

Supplementary Materials: The following are available online at https:/ /www.mdpi.com/2673-407 9/2/1/4/s1, Figure S1: Flow chart of film synthesis by solvent evaporation or solvent casting method.

Author Contributions: Conceptualization, K.M.N., A.P. and P.B.; methodology, N.V., N.G. and K.S.; validation, N.V., N.G. and K.S.; formal analysis, S.D.; investigation, N.V. and N.G.; data curation, N.V., N.G., K.S. and S.D.; writing—original draft preparation, N.V. and N.G.; writing—review and editing, R.S.; visualization, N.V. and N.G.; supervision, K.M.N. and P.B.; project administration, P.B. All authors have read and agreed to the published version of the manuscript.

Funding: This research received no external funding.

Institutional Review Board Statement: Not applicable.

Informed Consent Statement: Not applicable.

Data Availability Statement: Data sharing not applicable.

Acknowledgments: N.V. would like to thank the DST-INSPIRE Scheme, Department of Science and Technology, New Delhi, for a fellowship during doctoral studies. N.G. acknowledges UGC for fellowship to pursue doctoral studies. N.V., N.G., and K.S. acknowledge AcSIR, Ghaziabad \& CSIRNIIST Thiruvananthapuram for doctoral degree registration.

Conflicts of Interest: The authors declare no conflict of interest.

\section{References}

1. Volova, T.; Demidenko, A.; Kiselev, E.; Baranovskiy, S.; Shishatskaya, E.; Zhila, N. Polyhydroxyalkanoate synthesis based on glycerol and implementation of the process under conditions of pilot production. Appl. Microbiol. Biotechnol. 2019, 103, 225-237. [CrossRef] [PubMed]

2. Soto, L.R.; Byrne, E.; van Niel, E.W.; Sayed, M.; Villanueva, C.C.; Hatti-Kaul, R. Hydrogen and polyhydroxybutyrate production from wheat straw hydrolysate using Caldicellulosiruptor species and Ralstonia eutropha in a coupled process. Bioresour. Technol. 2019, 272, 259-266. [CrossRef] [PubMed]

3. Lunt, J. Large-scale production, properties and commercial applications of polylacticacid polymers. Polym. Degrad. Stab. 1998, 59, 145-152. [CrossRef]

4. Tajik, S.; Maghsoudlou, Y.; Khodaiyan, F.; Jafari, S.M.; Ghasemlou, M.; Aalami, M. Soluble soybean polysaccharide: A new carbohydrate to make a biodegradable film for sustainable green packaging. Carbohydr. Polym. 2013, 97, 817-824. [CrossRef] [PubMed] 
5. González, K.; Martin, L.; González, A.; Retegi, A.; Eceiza, A.; Gabilondo, N. D-isosorbide and 1,3-propanediol as plasticizers for starch-based films: Characterization and aging study. J. Appl. Polym. Sci. 2017, 134, 44793. [CrossRef]

6. Crouvisier-Urion, K.; Bodart, P.R.; Winckler, P.; Raya, J.; Gougeon, R.G.D.; Cayot, P.; Domenek, S.; Debeaufort, F.; Karbowiak, T. Biobased composite films from chitosan and lignin: Antioxidant activity related to structure and moisture. ACS Sustain. Chem. Eng. 2016, 4, 6371-6381. [CrossRef]

7. Yoshida, C.M.; Junior, E.N.O.; Franco, T.T. Chitosan tailor-made films: The effects of additives on barrier and mechanical properties. Packag. Technol. Sci. Int. J. 2009, 22, 161-170. [CrossRef]

8. Karthik, N.; Akanksha, K.; Binod, P.; Pandey, A. Production, purification and properties of fungal chitinases-A review. Indian J. Exp. Biol. 2014, 52, 1025-1035. [PubMed]

9. Aider, M. Chitosan application for active bio-based films production and potential in the food industry. Lwt-Food Sci. Technol. 2010, 43, 837-842. [CrossRef]

10. Leceta, I.; Guerrero, P.; de la Caba, K. Functional properties of chitosan-based films. Carbohydr. Polym. 2013, 93, 339-346. [CrossRef]

11. Leceta, I.; Guerrero, P.; Ibarburu, I.; Dueñas, M.; de la Caba, K. Characterization and antimicrobial analysis of chitosan-based films. J. Food Eng. 2013, 116, 889-899. [CrossRef]

12. Ma, X.; Qiao, C.; Zhang, J.; Xu, J. Effect of sorbitol content on microstructure and thermal properties of chitosan films. Int. J. Biol. Macromol. 2018, 119, 1294-1297. [CrossRef] [PubMed]

13. Martínez-Camacho, A.; Cortez-Rocha, M.; Ezquerra-Brauer, J.; Graciano-Verdugo, A.; Rodriguez-Félix, F.; Castillo-Ortega, M.M.; Yepiz-Gomez, M.S.; Plascencia-Jatomea, M. Chitosan composite films: Thermal, structural, mechanical and antifungal properties. Carbohydr. Polym. 2010, 82, 305-315. [CrossRef]

14. Bocqué, M.; Voirin, C.; Lapinte, V.; Caillol, S.; Robin, J.J. Petro-based and bio-based plasticizers: Chemical structures to plasticizing properties. J. Polym. Sci. Part A Polym. Chem. 2016, 54, 11-33. [CrossRef]

15. Sasikumar, K.; Vaikkath, D.K.; Devendra, L.; Nampoothiri, K.M. An exopolysaccharide (EPS) from a Lactobacillus plantarum BR2 with potential benefits for making functional foods. Bioresour. Technol. 2017, 241, 1152-1156. [CrossRef]

16. Vivek, N.; Pandey, A.; Binod, P. Biological valorization of pure and crude glycerol into 1,3-propanediol using a novel isolate Lactobacillus brevis N1E9.3.3. Bioresour. Technol. 2016, 213, 222-230. [CrossRef]

17. Vivek, N.; Aswathi, T.V.; Sven, P.R.; Pandey, A.; Binod, P. Self-cycling fermentation for 1,3-propanediol production: Comparative evaluation of metabolite flux in cell recycling, simple batch and continuous processes using Lactobacillus brevis N1E9.3.3 strain. J. Biotechnol. 2017, 259, 110-119. [CrossRef]

18. Vivek, N.; Pandey, A.; Binod, P. An efficient aqueous two phase systems using dual inorganic electrolytes to separate 1,3propanediol from the fermented broth. Bioresour. Technol. 2018, 254, 239-246. [CrossRef]

19. Rodríguez-Núñez, J.R.; Madera-Santana, T.J.; Sánchez-Machado, D.I.; López-Cervantes, J.; Valdez, H.S. Chitosan/hydrophilic plasticizer-based films: Preparation, physicochemical and antimicrobial properties. J. Polym. Environ. 2014, 22, 41-51. [CrossRef]

20. Priyadarshi, R.; Kumar, B.; Deeba, F.; Kulshreshtha, A.; Negi, Y.S. Chitosan films incorporated with Apricot (Prunus armeniaca) kernel essential oil as active food packaging material. Food Hydrocoll. 2018, 85, 158-166. [CrossRef]

21. Nagendra, B.; Mohan, K.; Gowd, E.B. Polypropylene/layered double hydroxide (LDH) nanocomposites: Influence of LDH particle size on the crystallization behavior of polypropylene. ACS Appl. Mater. Interfaces 2015, 7, 12399-12410. [CrossRef] [PubMed]

22. Hafsa, J.; ali Smach, M.; Khedher, M.R.B.; Charfeddine, B.; Limem, K.; Majdoub, H.; Rouatbi, S. Physical, antioxidant and antimicrobial properties of chitosan films containing Eucalyptus globulus essential oil. Lwt-Food Sci. Technol. 2016, 68, 356-364. [CrossRef]

23. Suyatma, N.E.; Tighzert, L.; Copinet, A.; Coma, V. Effects of hydrophilic plasticizers on mechanical, thermal, and surface properties of chitosan films. J. Agric. Food Chem. 2005, 53, 3950-3957. [CrossRef] [PubMed]

24. Kalaycıŏlu, Z.; Torlak, E.; Akın-Evingür, G.; Özen, İ.; Erim, F.B. Antimicrobial and physical properties of chitosan films incorporated with turmeric extract. Int. J. Biol. Macromol. 2017, 101, 882-888. [CrossRef] [PubMed]

25. Mobed-Miremadi, M.; Nagendra, R.K.; Ramachandruni, S.L.; Rook, J.J.; Keralapura, M.; Goedert, M. Polystyrene microsphere and 5-fluorouracil release from custom-designed wound dressing films. Prog. Biomater. 2013, 2, 1. [CrossRef] [PubMed]

26. Skornyakov, I.; Komar, V. Infrared spectra of structural modifications of dextran. J. Appl. Spectrosc. 1996, 63, 309-317. [CrossRef]

27. Muthulakshmi, L.; Annaraj, J.; Ramakrishna, S.; Ranjan, S.; Dasgupta, N.; Rangappa, S.M.; Siengchin, S. A sustainable solution for enhanced food packaging via a science-based composite blend of natural-sourced chitosan and microbial extracellular polymerics ubstances. J. Food Process. Preserv. 2021, 45, e15031. [CrossRef]

28. Kumirska, J.; Czerwicka, M.; Kaczyński, Z.; Bychowska, A.; Brzozowski, K.; Thöming, J.; Stepnowski, P. Application of spectroscopic methods for structural analysis of chitin and chitosan. Mar. Drugs 2010, 8, 1567-1636. [CrossRef]

29. Bhat, V.T.; James, N.R.; Jayakrishnan, A. A photochemical method for immobilization of azidated dextran onto aminated poly(ethyleneterephthalate) surfaces. Polym. Int. 2008, 57, 124-132. [CrossRef]

30. Ma, X.; Qiao, C.; Wang, X.; Yao, J.; Xu, J. Structural characterization and properties of polyolsplasticized chitosan films. Int. J. Biol. Macromol. 2019, 135, 240-245. [CrossRef]

31. Priyadarshi, R.; Kumar, B.; Negi, Y.S. Chitosan film incorporated with citric acid and glycerol as an active packaging material for extension of green chilli shelf life. Carbohydr. Polym. 2018, 195, 329-338. [CrossRef] [PubMed]

32. Nechita, P. Review on polysaccharides used in coatings for food packaging papers. Coatings 2020, 10, 566. [CrossRef]

33. Nešić, A.; Cabrera-Barjas, G.; Dimitrijević-Branković, S.; Davidović, S.; Radovanović, N.; Delattre, C. Prospect of PolysaccharideBased Materials as Advanced Food Packaging. Molecules 2020, 25, 135. [CrossRef] [PubMed] 
34. Epure, V.; Griffon, M.; Pollet, E.; Avérous, L. Structure and properties of glycerol-plasticized chitosan obtained by mechanical kneading. Carbohydr. Polym. 2011, 83, 947-952. [CrossRef]

35. Liu, H.; Adhikari, R.; Guo, Q.; Adhikari, B. Preparation and characterization of glycerol plasticized (high-amylose) starch-chitosan films. J. Food Eng. 2013, 116, 588-597. [CrossRef]

36. Lavorgna, M.; Piscitelli, F.; Mangiacapra, P.; Buonocore, G.G. Study of the combined effect of both clay and glycerol plasticizer on the properties of chitosan films. Carbohydr. Polym. 2010, 82, 291-298. [CrossRef] 